one cannot fail to marvel that he could draw the outline of the head so accurately as to enable a zoologist to identify the original model as the Indian species and to distribute its various errors with so much acumen.

Elliot Smith's ardent supporter, Mr. Perry, provides us with a fact that increases still more our amazement: the "movement of culture," he tells us, "that set out from Egypt" [always as stressed by Rivers without their women folk] " about the beginning of the fourth millennium B.C., ultimately landed in America [after centuries spent in India, Indonesia, and Polynesia] about the beginning of our era and there founded civilisations essentially the same as that of Egypt in the Pyramid Age. . . . This movement took 3000 years, more or less, to accomplish the journey, but it can be traced with fair accuracy for thousands of miles." It is therefore scarcely surprising not only that the god Indra was confused with Ganesa and that certain features -nose, ear, pinna, turbaned rider-of the elephant head during that period became but a memory to the bearers of the heliolithic civilisation to America, but that any resemblance even of the outline of its (tuskless) head and the appropriateness of a "driver" were so well conserved, especially as Elliot Smith assures us that the motive on the Stela was not the land elephant but "the sea-elephant design of the mythical Makara [a snouted monster with large prominent tusks and a fish's tail, which never existed on land or sea, and never carried a mahout] which was the commonest form of elephant spread abroad by the sea-men of Southern India copied from an earlier model (or picture, according to Elliot Smith) [made thousands of years before] by some immigrant from Asia." Imagine a picture-on what material soever depicted - surviving all these millenniums among a people who were only " food-gatherers" in the palæolithic stage when the heliolithic missionaries arrived among them !

Which is more likely to have inspired the Maya sculptor, a mythical animal, the memory of which 3000 years must have paled to obliteration, the outlines, moreover, of which had never been seen by any human eye ; or creatures familiar to him in his own seas, which must have excited his dread, and aroused his artistic sense?

I have to acknowledge Dr. Maudsley's photographs in the "Biologia" as the source of the above figures, and his kindness in permitting me to use them, and to thank Mr. J. Edge-Partington for sketching Fig. I for me.

\title{
The British Medical Association at Bradford.
}

\section{Tissue Culture.}

$\mathrm{A}^{\mathrm{T}}$ the ninety-second annual meeting of the British Medical Association held at Bradford on July 22.25, Dr. Alexis Carrel, of the Rockefeller Institute, New York, opened a discussion on the method of tissue culture and its bearing on pathological problems. The present position of tissue culture in vitro was clearly summarised, and considerable space was devoted to the most recent view of American workers that there are growth-promoting substancestrephones-which are secreted by certain cells of the body to minister to the nutritive wants of other cells. It is believed that leucocytic trephones play an important part in physiological and pathological processes. They secrete substances, in vitro and in vivo, and enable fibroblasts to grow readily.

\section{IMMUNITY.}

At the same meeting, Dr. R. A. O'Brien, of the Wellcome Physiological Research Laboratories, opened a discussion on immunity, with special reference to specificity and the influence of non-specific factors. It is now a hundred years since the great French clinician Bretonneau, from a mass of observations, set free the doctrine of specificity in disease. His particular contributions referred to enteric fever and diphtheria. After long years of confusion, Dr. William Budd, in the 'sixties of last century, again placed the doctrine of specificity on a sound basis, both with respect to enteric fever and to tuberculosis. The exact experiments of Robert Koch from 1876 onwards established the specificity doctrine on an irrefutable basis, which was again extended through the discovery of antitoxin by Behring and Kitasato in 1890 . Since that time every well-authenticated observation on man or animals has confirmed the specificity of infective virus.

It has been claimed, however, that certain substances which are non-specific in the sense that they have no direct or immediate affinity with the specific causes of disease, may act in a curative manner. It is the published data on this point which Dr. O'Brien has analysed. In certain instances he has subjected the question to experimental inquiry, and has been unable to find evidence that non-specific substances influence favourably specific experimental infections or intoxications. Against this is a slowly growing mass of clinical observation, which seems to point to therapeutic successes in a variety of diseases. Protein substances such as occur in milk, blood serum, and egg are claimed to be endowed with curative properties believed to be great or even extraordinary. We have recently been asked to believe that injections of milk will cure duodenal ulcers.

Many clinical observations are without much value on account of their uncritical character and the complexity of the factors involved. This non-specific therapy may be a fashion in therapeutics. At all periods there have been many such. It is said that a new drug should be exhibited while it still cures. It is also well not to forget that medicine still retains many of the characteristics which it had nineteen hundred years ago, when Celsus wrote, "Medicine is a conjectural art, and the nature of conjecture is such that although it answers for the most part, yet sometimes it fails."

\section{The Microscopy of the Living Eye.}

When von Graefe first saw the fundus of the living eye with Helmholtz's ophthalmoscope in 1858 , he is said to have exclaimed, "Helmholtz has unfolded to us a new world! What remains to be discovered!" Indeed it is questionable whether any single physical invention has been a greater boon to medical science than the ophthalmoscope. The latest development of ophthalmoscopy is the microscopy of the living eye, the technique of which has been elaborated by several ophthalmologists, but chiefly by the celebrated Allvar Gullstrand of Uppsala. Briefly stated, the method consists of illuminating the living eye by a narrow beam of light furnished by a nitra slit-lamp and condenser, and with diaphragms of various small apertures. The details of the structures so illuminated are observed obliquely, either by the "teleloup" or Czapski's binocular microscope. The teleloup consists of a pair of minia. ture opera-glasses fixed on a spectacle frame. It gives a stereoscopic image with a magnification of about two diameters. With the microscope, nine diameters or more of magnification can be obtained. 
The practical value of this new method of microophthalmoscopy formed the subject of an interesting discussion in the Ophthalmological Section, from which it is obvious that it has already yielded results of considerable scientific and practical interest. In opening the discussion, Mr. Basil Graves dealt with the physiological aspect of these results. He showed that it was possible by delicate adjustment of the illumination to demonstrate that the aqueous humour, the most pellucid of the body fluids, is not absolutely transparent, but that the range of what might be regarded as normal relucency could be determined. $\mathrm{He}$ has also detected varying degrees of metallic lustre in the crystalline lens, which he attributes to internal reflection from the lamellar surfaces in the interior of the lens itself.

Dr. Harrison Butler's résumé of the diagnostic aids which the new technique has already yielded in his hands affords an ample justification for its introduction into the practice of ophthalmology, and gives promise of further useful developments. The exact depth to which ulcerations have extended, and the localisation and extent of inflammatory processes in the cornea, can be determined with accuracy. The various forms of cataract can be detected in their earliest stages, and differentiated from one another with greater precision than heretofore. As the subsequent course and the treatment required for these several forms of cataract are widely different, it is, of course, important to be able to distinguish them early and surely. Another highly important application is in the early diagnosis of the much-dreaded sympathetic ophthalmia, by which disease many perfectly sound eyes are lost as the result of septic infection of the opposite eye. If the diagnosis is made sufficiently early, the good eye can be saved by prompt removal of the damaged eye. The detection of slight increase of turbidity of, or minute floating particles in, the fluid in the anterior chamber is the danger signal in this condition. Most of the points touched upon by the openers of the discussion are much better appreciated by demonstration than by description, consequently the interest of the meeting was focussed largely on the drawings and figures by which the papers were illustrated.

\section{Edinburgh Conference on the Vegetative Propagation of Plants.}

TO botanists and horticulturists all over the world the fame of the Botanic Garden at Edinburgh requires little comment. The collection of trees and shrubs is one of its many features; its Rock Garden alone has made it famous. So remarkable is the collection that a leading botanist from abroad was struck, not by the vast number of interesting plants, but by the fact that there are so few uninteresting ones. But the plants which meet the eye of the visitor are largely the production of that deft manipulation in the propagating pits screened from the general view, where much patient work is apt to be overlooked. Only those who have had the experience know the difficulties which so often beset the gardener who has to deal with the growing of a large representation of the world flora.

To make more generally known some of the experiences gained in the Royal Garden at Edinburgh, a well-attended Conference on the Vegetative Propagation of Plants was held on July I 7 and 18 under the auspices of the Botanical Society of Edinburgh. By permission of Prof. W. Wright Smith, Regius Keeper, the meeting was conducted at the Garden, and in the large laboratory attached thereto there was on exhibition about 300 species of seed-plants, supplemented by nearly 200 photographs, illustrating various methods of propagation from stem, root, and leaf as practised by Mr. L. B. Stewart, who is in charge of the Department of Propagation. Some of the results obtained in actual practice are remarkable enough in themselves, but an added interest lies in the wide field for anatomical and physiological investigation which they throw open. It is fortunate that close co-operation exists between the Garden and the University Department of Botany, and numerous problems arising out of the experience of the cultivator are under investigation at the hands of the botanist.

Certain specific questions have already received attention and these were brought before the Conference. Thus, in the genus Clematis, it is found that stem-cuttings root freely when the cutting is made through an internode but usually not at all if cut at the node. Miss Edith Philip Smith dealt with this problem and showed that the peculiarity may be related to the large amount of sclerenchymatous tissue occurring at the nodes, since it is found that if stems are etiolated before the cuttings are prepared, rooting from the node takes place readily. Etiolation is considered to act in two ways, resulting in a softening of the mechanical tissues of the stem and in a restoration of the carbon-nitrogen ratio which is regarded as necessary for establishing meristematic activity.

Mr. L. B. Stewart dealt with the propagation of plants possessing horizontal branches, taking Napoleona and Gardenia as special cases. In the former, a non-orthotropic branch-cutting gives rise to a new individual which fails to establish a vertical shoot axis. In the course of time, however, an adventitious bud may develop from the root system to produce an ordinary orthotropic stem. In Gardenia, a cutting prepared from a horizontal branch leads to the establishment of a new plant quite distinct in growth-form from the parent. No leading shoot is formed and horizontal branching does not occur; moreover, the new individual is precocious in flowering. Mr. Stewart discussed also the results of propagation from roots, dealing especially with Pelargonium and Acanthus montanus. In the latter, the form of plants raised from root-cuttings is juvenile or adult according to whether young or old portions of the root are used.

Propagation by means of leaves formed the subject of a communication by Dr. R. J. D. Graham. In leaf-cuttings of dicotyledons which do not possess succulent leaves the root system is first established, followed by the development of the shoot. The time of appearance of the shoot seems to depend to some extent on the viability of the leaf. In monocotyledons, however, shoot buds appear before the formation of roots, and succulent leaves of dicotyledons behave in the same way.

Dr. Graham gave an account also of the propagation of bulbous plants by making use of the bulb scales. In Ornithogalum, Drimia, and Hæmanthus, isolated bulb scales are exposed to sunlight to allow the mucilage of the injured surface to dry. The leaf bases are then laid on sand, watered once in ten days, and within four weeks numerous bulbils begin to develop on the adaxial side of the scales. This provides a quick method of obtaining large supplies of saleable bulbs. The induced buds arise in Ornithogalum from meristematic tissue near the leaf base. In Drimia, bud formation may be induced either in the parenchyma cells of the scale or in the callus formed on the injured surface. In Hæmanthus, buds arise from the hypodermal layers of the detached leaf base.

$$
\text { NO. } 2857 \text {, vOL. I I } 4]
$$

